\title{
Americans are told to wear cloth masks
}

\author{
Janice Hopkins Tanne
}

New York, USA

The US Centers for Disease Control and Prevention (CDC) has told Americans to wear cloth masks to prevent coronavirus transmission. President Donald Trump said at a press briefing last week that the advice was voluntary, and he was choosing not to wear one.

Trump said that the next week or two would be bad and there would be many deaths. The pandemic is expected to peak in the next week or two in New York.

In a television interview, Surgeon General Jerome Adams said the next week or two would be a 911 or Pearl Harbour moment for Americans. White House coordinator Deborah Birx told Americans to stay home, not to go to the grocery store or pharmacy, and do everything to protect themselves and their families.

In New York, there were slightly fewer deaths on Saturday than on Friday. The city continues to need supplies of masks, gowns, and ventilators.

The effectiveness of cloth masks in preventing transmission of infection has received very little study. A randomised controlled clinical trial comparing cloth masks with medical masks, published in BMJ Open in 2015, found that healthcare workers on high risk hospital wards who used cloth masks "had higher rates of infection than even the standard practice control group of health workers, and the filtration provided by cloth masks was poor compared with surgical masks." ${ }^{11}$ Since the start of the covid-19 pandemic the authors have been asked whether healthcare workers should wear no mask rather than a cloth mask. In an update to the article they said, "Our research does not condone health workers working unprotected. We recommend that health workers should not work during the covid-19 pandemic without respiratory protection as a matter of health and safety."

The US has 337933 cases of covid-19 and 9653 deaths as of Monday morning, according to Johns Hopkins University. New York State had 122031 cases and 4159 deaths as of 5 April, according to the New York Times. Most of the cases are in New
York City, which had 64955 cases and 2472 deaths as of Friday evening.

New York State governor Andrew Cuomo said on 2 April that the state had only a six day supply of ventilators left. He has complained of not receiving enough ventilators from the federal government and said that states had been forced to compete with one another in attempts to buy them.

New York City Mayor Bill de Blasio told city residents to cover their faces when going outdoors. The New York Times printed a mask pattern and instructions for making one in its 2 April edition.

The city's hospitals are crowded with patients with covid- 19 . A convention centre that was converted into a 2900 bed hospital was to take non-covid-19 patients but will now take only those with covid-19. A hospital ship with 1000 beds has docked in the city and will take patients who do not have covid-19, but only a few have so far been sent there.

New York City emergency medical technicians, who are called when someone has a cardiac event, will try to revive the person in their ambulance using the same protocols as in an emergency department. But if they are unsuccessful, they will declare the person dead instead of transporting them to the emergency department for further attempts. Very few patients survive if the emergency technicians have not been successful.

The Medical Society of the State of New York reminded doctors of the ventilator allocation guidelines, developed five years ago by the state's health department, on who gets a ventilator. Patients most likely to die without a ventilator and those most likely to survive without a ventilator do not get one. ${ }^{2}$

1 Macintyre CR, Tham CD, Seale H, Chughtai A. Covid-19, shortages of masks and the use of cloth masks as a last resort. BMJ Open 2015;5:e006577.

10.1136/bmjopen-2014-006577 25903751

2 New York State Task Force on Life and the Law New York State Department of Health Ventilator allocation guidelines. 2015. www.health.ny.gov/regulations/task_force/reports_ publications/docs/ventilator_guidelines.pdf.

Published by the BMJ Publishing Group Limited. For permission to use (where not already granted under a licence) please go to http://group.bmj.com/group/rights-licensing/ permissions 